\title{
An Efficient Method for The Synthesis of Dihydropyridine by Hantzsch Reaction with $\mathrm{Fe} / \mathrm{SiO}_{2}$ Nano Heterogeneous Catalysts
}

\author{
Ateeq Rahman*, P.N. Nehemia, Moola M. Nyambe
}

Faculty of Science, Department of Chemistry and Biochemistry, University of Namibia, Mandume Ndemufayo Avenue, Private Bag 13301, Pionierspark Windhoek, Namibia.

Received: 26 ${ }^{\text {th }}$ April 2020; Revised: 21st July 2020; Accepted: 29th July 2020; Available online: $24^{h}$ August 2020; Published regularly: December 2020

\begin{abstract}
An efficient method for the synthesis of dihydropyridines (DHPs) by Hantzsch reaction with $\mathrm{Fe} / \mathrm{SiO}_{2}$ heterogeneous catalysts was developed. The $\mathrm{Fe} / \mathrm{SiO}_{2}$ catalysts was prepared by impregnation method. The catalysts were characterized by IR and SEM instruments. The SEM results indicated that $\mathrm{Fe} / \mathrm{SiO}_{2}$ nano spheres were formed. The reaction procedure involved reaction of aldehyde, ethyl acetoacetate (EAA), ammonium acetate $\left(\mathrm{NH}_{4} \mathrm{OAc}\right)$ and ethanol under reflux. The study was focused on optimizing reactions conditions: Standardization of catalyst, substrate of study and solvent study. In order to identify the best active catalysts, five different ratios of catalyst were synthesized and evaluated for the title reaction under similar conditions. To standardize the active catalysts, different temperature conditions (i.e. room temperature, $60{ }^{\circ} \mathrm{C}$ and $80{ }^{\circ} \mathrm{C}$ ) as well as catalysts amounts were evaluated. Under these established conditions, $2.5 \% \mathrm{Fe} / \mathrm{SiO}_{2}$ was the best active catalysts that resulted. Benzaldehyde and $p$-anisaldehyde were used to study the effect of having various substrates on the conversion and reaction time, especially the substituted aldehydes. The best results were obtained by reacting $p$ anisaldehyde with EAA, $\mathrm{NH}_{4} \mathrm{OAc}$, and ethanol at $60{ }^{\circ} \mathrm{C}$ with 0.3 grams of $2.5 \% \mathrm{Fe} / \mathrm{SiO}_{2}$ heterogeneous catalysts. Thin Layer Chromatography (TLC) monitoring of the reaction mixture showed no selectivity at high temperatures $\left(80{ }^{\circ} \mathrm{C}\right)$ with $15 \% \mathrm{Fe} / \mathrm{SiO}_{2}$. Standardization of solvent study was executed with two solvents, ethanol and acetonitrile. The product dihydropyridines were analyzed using gas chromatography-mass spectrometry (GC-MS). The melting points of the products were compared with authentic samples reported in the literature. Hence, the $\mathrm{Fe} / \mathrm{SiO}_{2}$ catalysts is eco-friendly and economically developed for the title reaction. Copyright (C) 2020 BCREC Group. All rights reserved
\end{abstract}

Keywords: Hantzsch reaction; dihydropyridines; impregnated; $\mathrm{Fe} / \mathrm{SiO}_{2}$ nano; heterogeneous catalyst

How to Cite: Rahman, A., Nehemia, P.N., Nyambe, M. (2020). An Efficient Method for The Synthesis of Dihydropyridine by Hantzsch Reaction with $\mathrm{Fe} / \mathrm{SiO}_{2}$ Nano Heterogeneous Catalysts. Bulletin of Chemical Reaction Engineering \& Catalysis, 15(3), 617-630 (doi:10.9767/bcrec.15.3.7669.617-630)

Permalink/DOI: https://doi.org/10.9767/bcrec.15.3.7669.617-630

\section{Introduction}

Hantszch reaction is a synthetic method of synthesizing dihydropyridines (DHPs) in a one-

\footnotetext{
* Corresponding Author.

E-mail: arahman@unam.na (A. Rahman)

Tel: +264-61-2064553
}

pot multicomponent reaction system consisting of an aryl aldehyde, acetoacetic ester, and ammonia heated in refluxing methanol for a few hours [1-2]. DHPs and their derivatives are common features found in vasodilator, antiatherosclerotic, anti-cancer, anti-diabetic and antihypertensive agents [3-4]. There are several methods are reported in literature for the syn- 
thesis of DHPs, of which most of them are limited to the modification and optimization of the Hantzsch multicomponent synthesis between an aldehyde, a 1,3-dicabonyl compound, and a source of ammonia [3,5]. Preparation of nifedipine, a dihydropyridine calcium channel blocker, acetoacetic acid methyl ester, methanol, and ammonia is used [1]. Some of the efficient methods reported for the synthesis of DHPs made use of metal triflates, $\mathrm{I}_{2}$, CAN-Cerium ammonium nitrate, $\mathrm{PPh}_{3}$ Triphenyl phosphine, L-proline, PoylPhosphoric acid supported silicaPPA-SiO $\mathrm{S}_{2}$, Lanthanum oxide $-\mathrm{La}_{2} \mathrm{O}_{3}$ and nickel nanoparticles $[3,5]$. Numerous catalysts have so far been evaluated for the title reaction with $\mathrm{Fe}_{3} \mathrm{O}_{4} /$ silica sulfonic acid nanocomposite [6], $\mathrm{Fe}_{2} \mathrm{O}_{3}, \mathrm{CuO}, \mathrm{ZnO}$ [1], and $\mathrm{Fe}_{3} \mathrm{O}_{4} / \mathrm{SiO}_{2}-\mathrm{NH}_{2}$ nanocomposite [7]. The classical method used to synthesize DHPs has disadvantages such as long reaction times, harsh refluxing condition, excessive use of volatile solvents and low yields which precludes the wide use of these reagents [3]. For example, $\mathrm{Fe}_{3} \mathrm{O}_{4} / \mathrm{SiO}_{2}-\mathrm{NH}_{2}$ takes four hours to yield 94\% 1,4-DHP [7], $\mathrm{TiO}_{2} \mathrm{NPs}$ and Fe-TDU-1 [8]. Mvumvu [9] also indicated that due to the formation of side products, after several attempts to synthesize 1,4-DHP ester analogues from ethyl acetoacetate, the experiment was considered unsuccessful. The field of Nanocatalysis provides an alternative to homogeneous catalysts by using highly porous catalysts with a large surface area for reagents to interact with catalysts [3]. Hence, metal oxidecatalyzed organic reactions are efficient catalysts for the synthesis of valuable commodities in organic synthesis that are more desirable in green chemistry point of view. Authors have developed a newer Green chemistry route for Hantzsch reaction of various aldehydes with ethyl acetoacetate and ammonium acetate in a $\mathrm{Fe} / \mathrm{SiO}_{2}$ at $80{ }^{\circ} \mathrm{C} . \mathrm{Fe} / \mathrm{SiO}_{2}$ acts as an efficient catalyst. Preparation of $\mathrm{Fe} / \mathrm{SiO}_{2}$ nano catalysts is easier than other nano metal oxides and due to the effect of optimum conditions such as temperature, kind of surfactant, medium, and the solvent on the crystallinity and catalytic properties of nano $\mathrm{Fe} / \mathrm{SiO}_{2}$ [7-12]. The call for envi- ronmentally benign procedure with heterogeneous catalysts prompted authors to develop a safe alternate, economic, green method for the synthesis of 1,4-dihydropyridines in the presence of $\mathrm{Fe} / \mathrm{SiO}_{2}$ (NPs) in shorter duration of time (Scheme 1).

\section{Materials and Methods}

\subsection{Materials}

Benzaldehyde $99.0 \%, \quad \mathrm{p}$-Anisaldehyde $99.0 \%$, p-Toulaldehyde $98.0 \%$, Silica gel 60 $\left(\mathrm{SiO}_{2}, 70-230\right.$ mesh ASTM), absolute ethanol $(99.5 \%)$, and reagent grade iron(III) nitrate $99.0 \%$ were purchased from Merck.

\subsection{Preparation of $\mathrm{Fe} / \mathrm{SiO}_{2}$ Catalyst}

All chemicals were procured from Merck. For $2.5 \% \mathrm{Fe} / \mathrm{SiO}_{2}$, ferric nitrate $\mathrm{Fe}\left(\mathrm{NO}_{3}\right)_{3}$ solution was prepared by dissolving $0.625 \mathrm{~g}$ of $\mathrm{Fe}\left(\mathrm{NO}_{3}\right)_{3} .9 \mathrm{H}_{2} \mathrm{O}$ in $25 \mathrm{~mL}$ distilled water. The solution obtained was then transferred to a round bottom flask equipped with a refluxing device. Solid $\mathrm{SiO}_{2}$ (2.0344 g) was rapidly added to the solution. The mixture was then stirred for 3 hours at room temperature $/ 25{ }^{\circ} \mathrm{C}$. Water was evaporated off from the catalyst and dried in an oven at $100{ }^{\circ} \mathrm{C}$ for overnight. The other ratios of catalysts such as 5.0, 7.5, 10, and 15\% were prepared using the same procedure used for $2.5 \% \mathrm{Fe} / \mathrm{SiO}_{2}$ [24]. A JEOL JSM-6100 Scanning Electron Microscope (SEM) was used to study the morphology and surface topography of the $\mathrm{Fe} / \mathrm{SiO}_{2}-\mathrm{NPs}$. Fourier Transform Infrared (FTIR) analysis was carried out using a FT-IR Perkin Elmar Spectrum 2 Spectrometer to study the functional group $\mathrm{OH}$ present in $\mathrm{SiO}_{2}$.

\subsection{Typical Procedure for Synthesis of DHPs}

A solution of aldehyde (1 mmol), ethyl acetoacetate $(2 \mathrm{mmol})$, ammonium acetate $(2 \mathrm{mmol})$ and ethanol $(10 \mathrm{~mL})$ at reflux conditions was reacted in the presence of $\mathrm{Fe} / \mathrm{SiO}_{2}$ catalyst $(0.3022 \mathrm{~g})$. The resulting mixture was stirred until the TLC-Thin Layer Chromatography

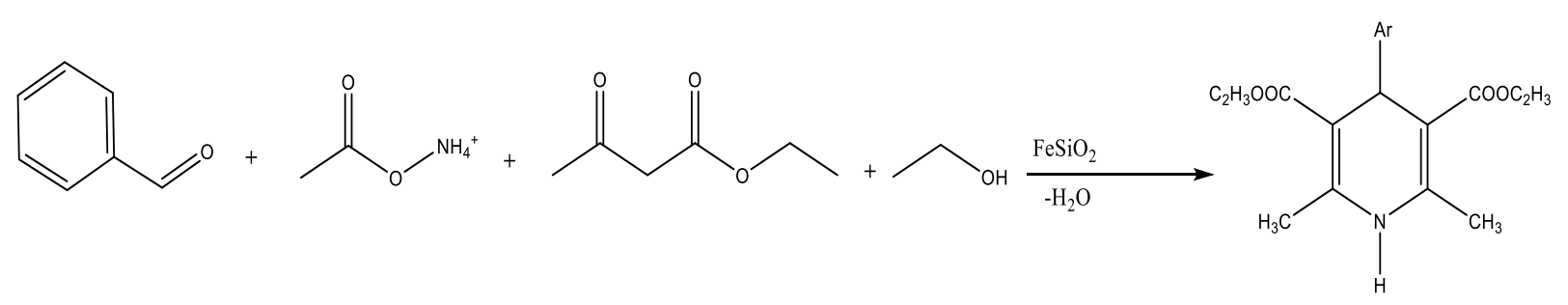

Scheme 1. Various substrate evaluated with $2.5 \% \mathrm{Fe} / \mathrm{SiO}_{2}$ catalysts. 
monitoring showed completion of the starting material. The reaction mixtures were cooled to room temperature and extracted with diethyl ether. Organic layer was dried over anhydrous $\mathrm{Na}_{2} \mathrm{SO}_{4}$. After evaporation of the solvent, the obtained yellow products were purified by crystallization from ethanol. After crystallization the solvent was concentrated at reduced before subjecting to GC-Mass analysis. And the final yield of product were obtained Table 1.

\subsection{GC-MS Instrument Specifications}

The GC-MS analyses were performed on a Thermo Scientific Focus GC coupled to an ITQ 700 MS using helium as carrier gas at a flow rate of $1.0 \mathrm{~mL} / \mathrm{min}$ (constant flow) and a split ratio of 10. A SGE BP5MS capillary GC column (30 $\mathrm{m} \times 0.25 \mathrm{~mm}$ i.d) with volume of $5 \%$ diphenyl, $95 \%$ dimethyl polysiloxane stationary phase $(0.25 \mathrm{\mu m}$ film thickness) was used for the separations. FID (Flame Ionization Detec-

Table 1. Summary of standardization of $\mathrm{Fe} / \mathrm{SiO}_{2}$ catalysts.

\begin{tabular}{|c|c|c|c|c|c|c|c|c|}
\hline $\begin{array}{l}\text { S. } \\
\text { No }\end{array}$ & $\begin{array}{l}\text { Sub- } \\
\text { strate }\end{array}$ & $\begin{array}{c}\text { Catalyst } \\
\left(\% \mathrm{Fe} / \mathrm{SiO}_{2}\right)\end{array}$ & $\begin{array}{c}\text { Grams of } \\
\mathrm{Fe} / \mathrm{SiO}_{2} \\
\text { catalysts (g) }\end{array}$ & $\begin{array}{c}\text { Ethanol } \\
\text { Solvent } \\
(\mathrm{mL}) \\
\end{array}$ & $\begin{array}{l}\text { Reflux } \\
\text { Temp. } \\
\left({ }^{\circ} \mathrm{C}\right) \\
\end{array}$ & $\begin{array}{l}\text { Time } \\
\text { taken } \\
(\min ) \\
\end{array}$ & $\begin{array}{c}\text { Yield } \\
\% \mathrm{a}^{\mathrm{a}}\end{array}$ & $\begin{array}{c}\text { Selectivity } \\
\%\end{array}$ \\
\hline \multirow{8}{*}{1.} & \multirow{8}{*}{$\begin{array}{l}\text { Benzal- } \\
\text { dehyde + } \\
\text { EAA + } \\
\mathrm{NH}_{4} \mathrm{OAc}\end{array}$} & 2.5 & 0.3022 & 10 & 60 & 122 & 89 & 90 \\
\hline & & 5.0 & 0.3056 & 10 & 60 & 125 & 83 & 0 \\
\hline & & 7.5 & 0.3058 & 10 & 60 & 110 & 70 & 0 \\
\hline & & 10 & 0.3078 & 10 & 60 & 65 & 77 & 0 \\
\hline & & & 0.5050 & 10 & $\mathrm{RT}^{\mathrm{b}}$ & 168 & 68 & 0 \\
\hline & & & 0.5058 & 10 & 60 & 258 & 78 & 0 \\
\hline & & 15 & 0.5058 & 10 & 80 & 120 & 66 & 0 \\
\hline & & & 0.3022 & 10 & 60 & 108 & 79 & 0 \\
\hline
\end{tabular}

asolated yield; bRoom temperature $\left(25^{\circ} \mathrm{C}\right)$

Table 2. Comparison of $\mathrm{Fe} / \mathrm{SiO}_{2}$ catalyst (Table 1) with various catalysts reported in literature.

\begin{tabular}{|c|c|c|c|c|c|c|}
\hline $\begin{array}{l}\text { S. } \\
\text { No } \\
\end{array}$ & Catalysts & Solvent & $\begin{array}{c}\text { Temp } \\
\left({ }^{\circ} \mathrm{C}\right) \\
\end{array}$ & Time & $\begin{array}{l}\text { Conver- } \\
\text { sion (\%) }\end{array}$ & Reference \\
\hline 1. & $\mathrm{P}_{2} \mathrm{O}_{5}-\mathrm{SiO}_{2}$ & $\mathrm{CHCl}_{3}$ & 110 & $4 \mathrm{~h}$ & 85 & {$[13]$} \\
\hline 2. & ZnO Nano & $\mathrm{H}_{2} \mathrm{O}$ & 60 & $2-4 \mathrm{~h}$ & 90 & {$[1]$} \\
\hline 3. & Chitosan Nano & Solvent free & 80 & $4 \mathrm{~h}$ & 55 & {$[15]$} \\
\hline 4. & $\mathrm{FeCl}_{3} \mathrm{NPS}$ & Ethanol & Reflux & $2 \mathrm{~h} 30 \mathrm{~min}$ & 41 & {$[1]$} \\
\hline 5. & $\mathrm{~V}_{2} \mathrm{O}_{5} / \mathrm{SiO}_{2}$ & Acetic acid & 40 & $13 \mathrm{~min}$ & 100 & {$[14]$} \\
\hline 6. & $\mathrm{La}_{2} \mathrm{O}_{3} / \mathrm{TFE}$ & THF & $\mathrm{RT}^{\mathrm{a}}$ & $1-1.5 \mathrm{~h}$ & 90 & {$[3,17]$} \\
\hline 7. & Polymer & Solvent free & 120 & $20 \min$ & 72 & {$[16]$} \\
\hline 8. & Cyclodextrin & $\begin{array}{l}\text { N,N dimethyl } \\
\text { formamide }\end{array}$ & 80 & $3 \mathrm{~h}$ & $10-90$ & {$[20]$} \\
\hline 9. & $\mathrm{TiO}_{2} \mathrm{NPs}$ & Ethanol & 80 & 135 mins & 65 & [8] \\
\hline 10. & Fe-TDU-1 & Ethanol & 80 & $300 \mathrm{mins}$ & 60 & {$[8]$} \\
\hline 11. & $\mathrm{Yb}(\mathrm{OTf}) 3(5 \mathrm{~mol} \%)$ & EtOH & $\mathrm{RT}^{\mathrm{a}}$ & $2-8 \mathrm{~h}$ & $85-95$ & {$[18]$} \\
\hline 12. & $\mathrm{Sc}(\mathrm{OTf})(5 \mathrm{~mol} \%)$ & $\mathrm{EtOH}$ & $\mathrm{RT}^{\mathrm{a}}$ & $2-6 \mathrm{~h}$ & $85-95$ & {$[19]$} \\
\hline 13. & $\begin{array}{l}\text { (PTSA) 4-Toluene } \\
\text { sulphonic acid }\end{array}$ & Solvent free & $\mathrm{RT}^{\mathrm{a}}$ & $36 \min$ & 50 & {$[21]$} \\
\hline
\end{tabular}

aRoom temperature $\left(25^{\circ} \mathrm{C}\right)$ 
tor) is used. The $10 \mathrm{mg}$ of the intermediate 1a sample was dissolved in $1.5 \mathrm{~mL}$ of ethyl acetate and 1.5 of dichloromethane for analysis.

\section{Results and Discussion}

The search for new readily available and green methods is still ongoing [5], thus in this study, a new catalyst $\mathrm{Fe} / \mathrm{SiO}_{2}$ was prepared by simple impregnation method was developed and evaluated for its catalytic activity for the title reaction. The Hantzsch condensation for three substrate's of different functionality were studied namely benzaldehyde, $p$-anisaldehyde and toulaldehyde at reflux in ethanol solvent (Scheme 1). Saini et al. [3] reported with the chemistry of 1,4-DHPs with ethanol solvent which is proven to be better than other alcohols

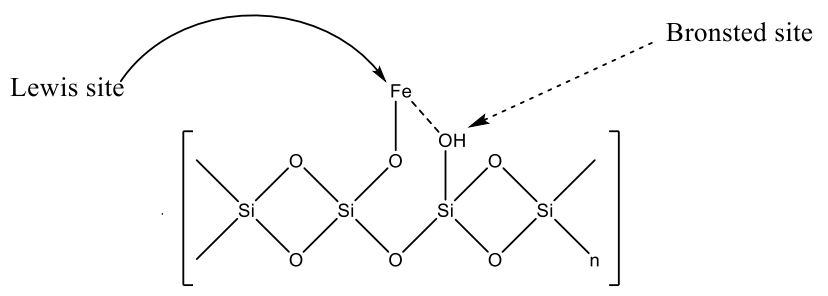

Scheme 2. Bronsted acidity arising from inductive effect of Lewis acid center coordinated to nanosilica support. such as isopropanol, methanol. It has some advantages over the other methods such as the amount of water formed in the reaction, which is a fundamental aspect of Hantzsch 1,4-DHP synthesis employing sterically demanding benzaldehydes [25]. The reactions were monitored by TLC (9:1 $\mathrm{CH}_{2} \mathrm{Cl}_{2}$ /AcOEt as eluent) until the disappearance of the starting benzaldehyde, anisaldehyde and taulaldehyde. With anisaldehyde the reactions were completed after $1 \mathrm{~h} 36$ mins and for benzaldehyde in $2 \mathrm{~h}$ which is short time period reported in literature (Table 2) which is 5,6 and $8 \mathrm{~h}$ duration of time $[8,18,19]$. With $2.5 \% \mathrm{Fe} / \mathrm{SiO}_{2}$ catalysts, the reaction was fast took place.

\subsection{Standardization of Catalyst}

Various experiments were conducted using six different ratios of $\mathrm{Fe} / \mathrm{SiO}_{2} 2.5,5,7,10$, and $15 \%$ for each reaction with benzaldehyde. The main aim of this methodology was to evaluate the most suitable $\mathrm{Fe} / \mathrm{SiO}_{2}$ catalysts among these ratios under standards conditions. Optimization of reaction parameters, i.e. the temperature, time and amount of catalyst were also studied Table 1 . Table 1 shows the results obtained for the reaction of benzaldehyde at different temperatures. It was observed that at high catalyst ratios there was less conversion

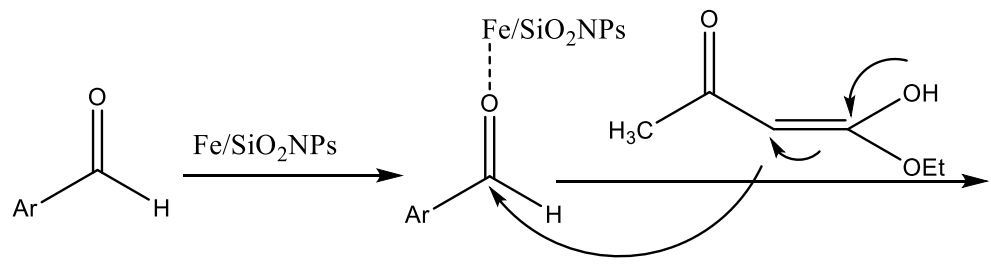

(c)

(II)<smiles>CCOC(=O)C(C=O)C(C)=O</smiles>

(I)<smiles>CCOC(=O)C(=O)C(C(=O)OCC)C(C(C)=N)C(C(C)=O)C(=O)OCC</smiles>

Scheme 3. The proposed mechanism of the synthesis of 1,4-dihydropyridines in the presence of silica (NPs) supported Fe(III). 
for example $\left(15 \% \mathrm{Fe} / \mathrm{SiO}_{2}\right.$ lowest yield $66 \%$ of hours at high temperature of $80{ }^{\circ} \mathrm{C}$ and $68 \%$ yield over of period of 2 hours 48 minutes at room temperature (Table 1). This could be due to uneven distribution of Fe on Silica [24]. Another study reported a selectivity of zero observed for $\mathrm{Ni} / \mathrm{SiO}_{2}$ catalysts reported [24]. The $10 \% \mathrm{Fe} / \mathrm{SiO}_{2}$ catalyst gave the best results of $77 \%$ yield in 65 minutes which is a short time Table 1. $2.5 \% \mathrm{Fe} / \mathrm{SiO}_{2}$ resulted into $89 \%$ conversion in $1 \mathrm{~h} 36$ minutes (122 minutes) was obtained Table 1 . The $2.5 \% \mathrm{Fe} / \mathrm{SiO}_{2}$ catalysts gave $90 \%$ yield. Hence, with 5, 7.5, 10, and $15 \%$ $\mathrm{Fe} / \mathrm{SiO}_{2}$ selectivity was $0 \%$. The blank reactions were also evaluated where $\mathrm{Fe}\left(\mathrm{NO}_{3}\right)_{3}$, and $\mathrm{SiO}_{2}$ NPs involving substrates and solvent were used and these gave $0 \%$ yield after $3 \mathrm{~h}$, $\mathrm{Fe}\left(\mathrm{NO}_{3}\right)_{3} 1 \mathrm{~h} 30$ minutes yield $35 \%, \mathrm{SiO}_{2} \mathrm{NPs} 1$ h 30 minutes yield $20 \%$ in standardized conditions.

Table 2 represents various catalysts that have been reported for Hanzsch reactions and the yields are varying between $10-95 \%$. Almost all the catalysts took longer duration of time from $2-8 \mathrm{~h}$ to complete the reactions. This confirms less activity of $\mathrm{P}_{2} \mathrm{O}_{5}-\mathrm{SiO}_{2}$ entry1, $\mathrm{Yb}(\mathrm{OTf})_{3}$ (5 mol\%) entry 11, Sc(OTf) (5 mol\%) entry 12 and these catalysts took $8 \mathrm{~h}$ of dura-
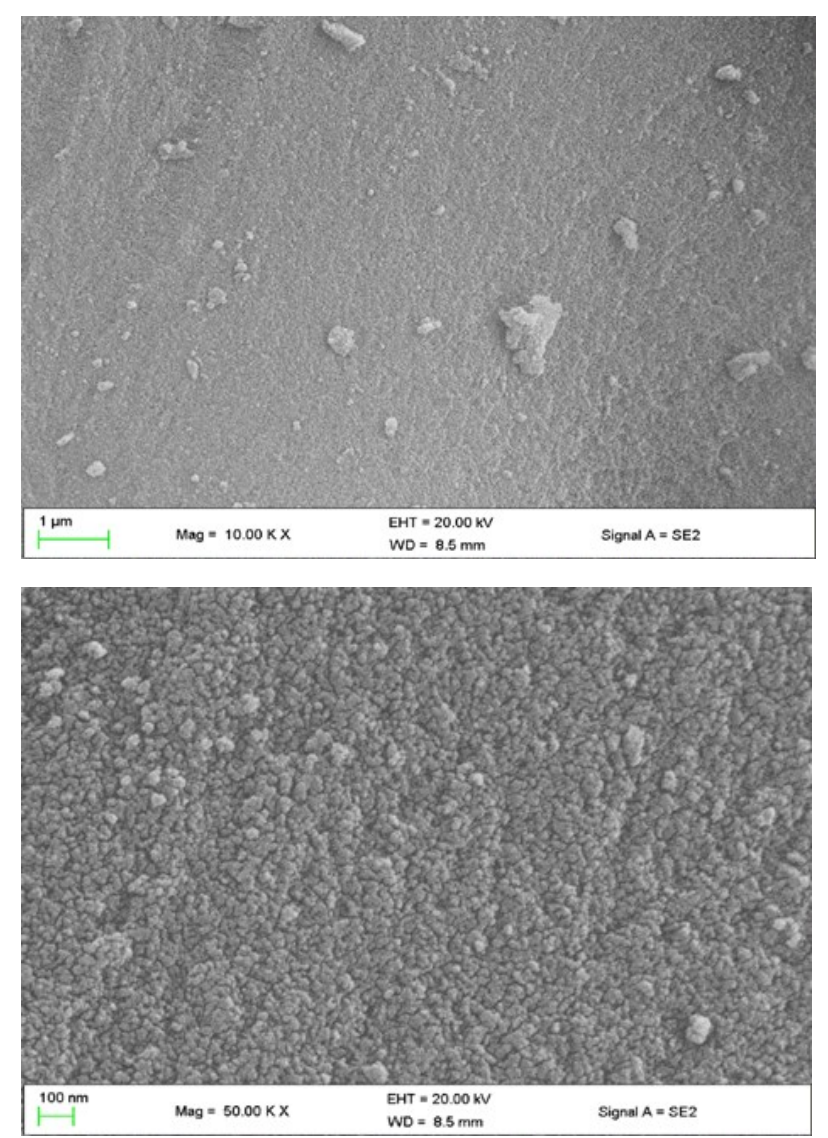

tion to complete the reaction Table 2 . This is ascribed due to the active sites of the catalysts which are inactive. From this data, it can be deduced that $\mathrm{Fe} / \mathrm{SiO}_{2}$ Nano catalyst is more active giving $89 \%$ conversion in $2 \mathrm{~h}$ entry 1 (Table 1) compared to the catalysts listed in Table 2 [24].

As illustrated in Scheme 2, the silica supported $\mathrm{Fe}(\mathrm{III})$ can act as Bronsted and Lewis acid catalysts [23]. Mechanism of $\mathrm{Fe} / \mathrm{SiO}_{2} \mathrm{NPs}$ within reaction: In this mechanism, the author's propose that an acid-base interaction between silica supported $\mathrm{Fe}$ (III) and loan pair of oxygen polarizes $\mathrm{C}=\mathrm{O}$ bond of aldehyde. Hence the Knoevenagel product (I) and ester enamine (II) were prepared by this interaction. While the condensation of these two fragments gives intermediate (III) which subsequently cyclizes to the 1,4-dihydropyridine Scheme 3 [1].

\subsection{Characterization of Catalyst}

Characterization of the catalyst was done using scanning electron microscopy (SEM), electron dispersive x-ray (EDX), and infrared spectroscopy (IR). The $2.5 \%$ and $7.5 \% \mathrm{Fe} / \mathrm{SiO}_{2}$ ratios were analyzed with SEM and EDX. IR was used for characterization of $2.5 \%$ and $5 \%$ $\mathrm{Fe} / \mathrm{SiO}_{2}$ (Figure 4) SEM, EDX, EDX layered images analysis results for $2.5 \%$ are shown in Figures 1-3.

\subsubsection{X-Ray diffraction XRD}

The XRD of all samples showed diffuse pattern 2 theta value was 25 for $\mathrm{Si}-\mathrm{O}-\mathrm{Si}$ bond showed crystalline pattern of silica similar to the one reported by Jonnalagadda et al. [24].

\subsubsection{Scanning electron microscopy (SEM)}

SEM analysis of $\mathrm{Fe} / \mathrm{SiO}_{2}$ catalysts shows the morphology and size of the particles of the syn-

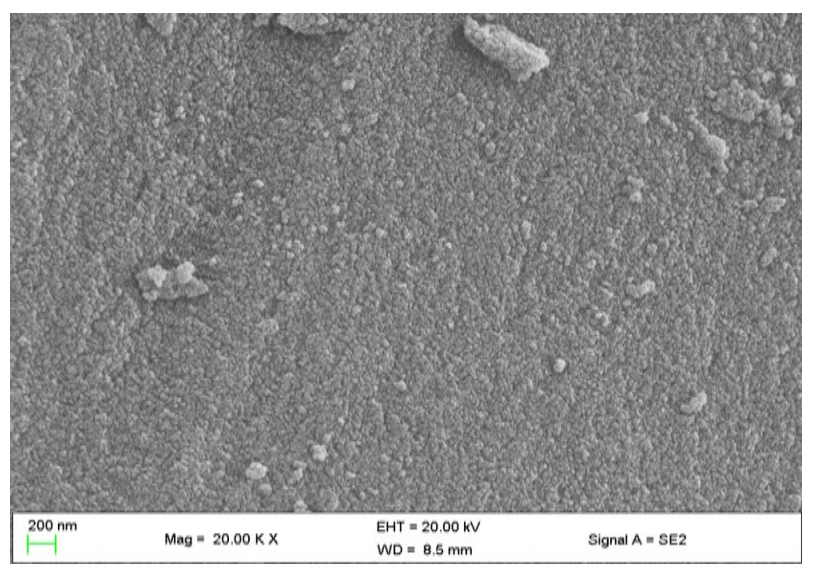

Figure 1. SEM images for $2.5 \% \mathrm{Fe} / \mathrm{SiO}_{2}$ catalyst. 
thesized. The catalyst was synthesized in nano and micrometer ranges as shown in the SEM image Figure 1 where particles are widely spread [24]. From the Figures 1 and 2 it can be seen that with $2.5 \% \mathrm{Fe} / \mathrm{SiO}_{2}$ it is confirmed that the $\mathrm{Fe}$ is dispersed homogenously on the $\mathrm{SiO}_{2}$ surface. $\mathrm{Fe}$ loading with $7.5 \%$ one has 6.91 , which is very close to the anticipated loading. But, the $2.5 \%$ sample got $5.74 \%$ of $\mathrm{Fe}$, which is way above the anticipated loading. It is also evident from the EDX images that the $2.5 \% \mathrm{Fe}$, has some aggregation results that are identical reported by Anabi et al. [26]. Hence,

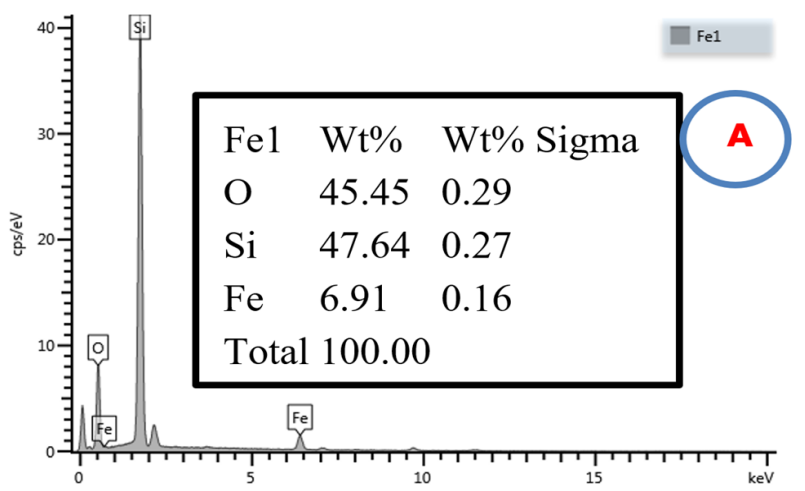

the gray particles is nano silica which are supported by $\mathrm{Fe}$ oxidized white particles [26]. From these finding its evident that $2.5 \%$ $\mathrm{Fe} / \mathrm{SiO}_{2} \mathrm{Fe}$ particles are uniformly distributed on silica and this is consistent with the results reported by Jonnalagadda et al. [24].

\subsubsection{Electron Dispersive X-ray}

Figure 2 shows elemental analysis of the samples by EDX. Comparing the two samples, Iron weight percent in $2.5 \% \mathrm{Fe} / \mathrm{SiO}_{2}$ is at $5.74 \%$, which is lower than that of $7.5 \%$

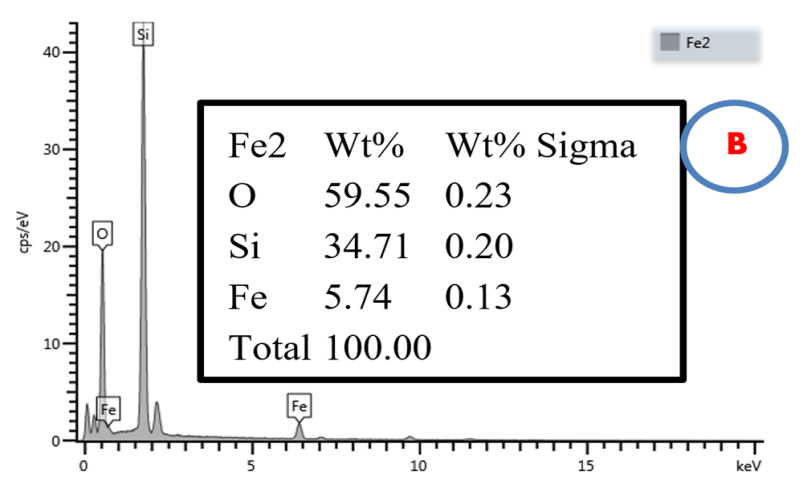

Figure 2. EDX analysis of $7.5 \% \mathrm{Fe} / \mathrm{SiO}_{2}(\mathrm{~A})$ and $2.5 \% \mathrm{Fe} / \mathrm{SiO}_{2}(\mathrm{~B})$.

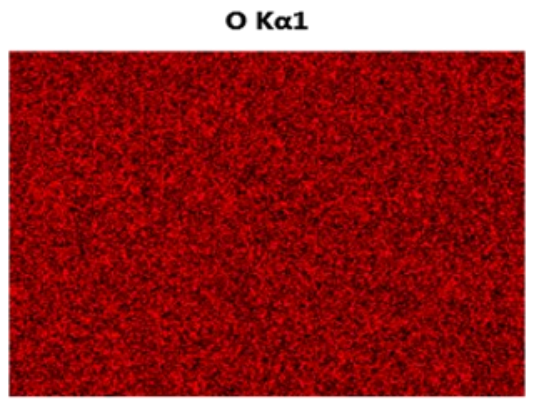

$\longdiv { 5 0 0 \mathrm { nm } }$
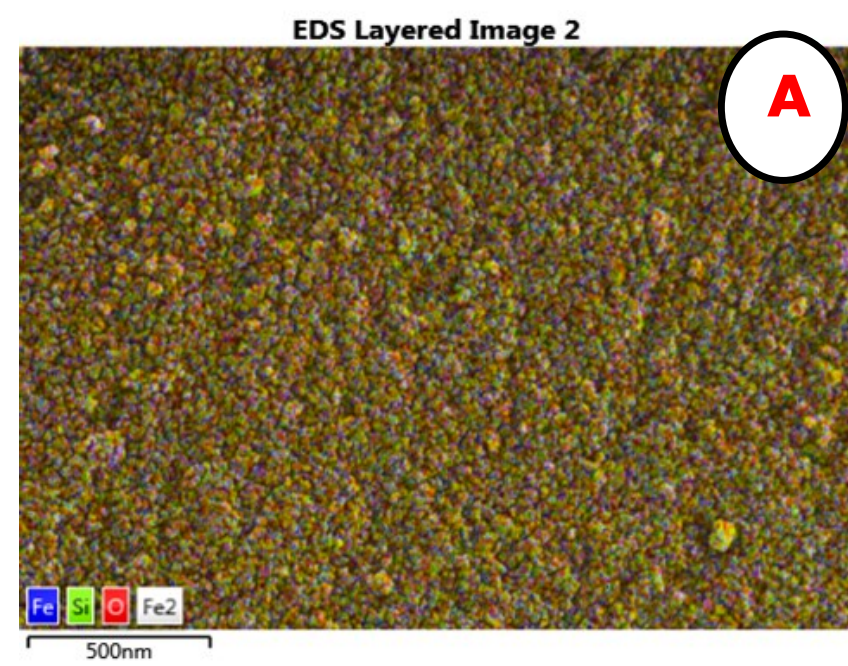

Si Ka1

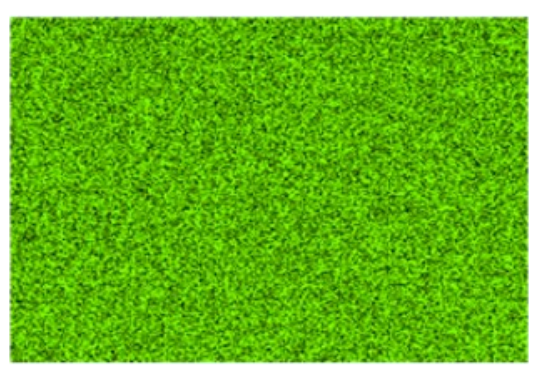

$\longdiv { 5 0 0 \mathrm { nm } }$

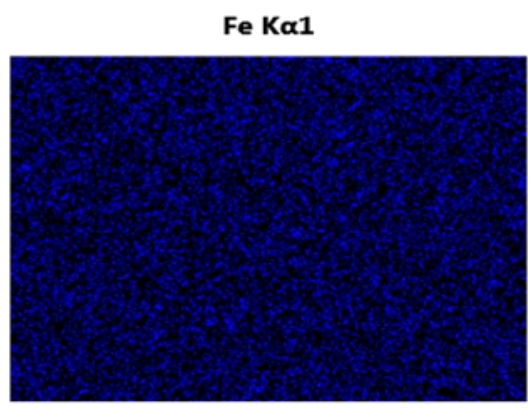

$\longdiv { 5 0 0 \mathrm { nm } }$

EDS Layered Image 1

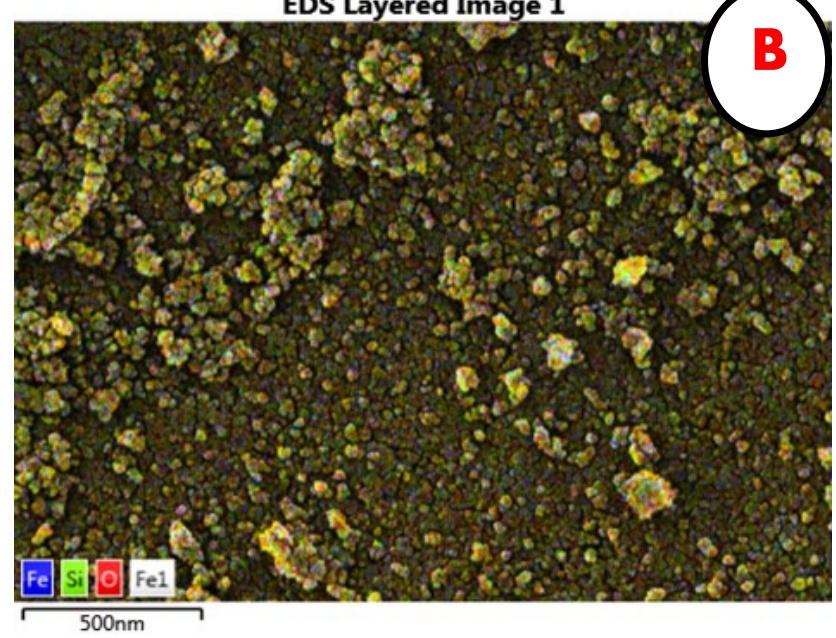

Figure 3. EDS layered images of $2.5 \% \mathrm{Fe} / \mathrm{SiO}_{2}(\mathrm{~A})$ and $7.5 \% \mathrm{Fe} / \mathrm{SiO}_{2}(\mathrm{~B})$ showing even distribution of $\mathrm{Fe}$ in A (best catalyst ratio) than in BB. 
$\mathrm{Fe} / \mathrm{SiO}_{2}$ at $6.91 \%$. This is ascribed due to the $2.5 \%$ and $7.5 \%$ loading of Fe samples observed for both samples [24]. The ratio of each element in each sample is indicated in the respective spectra and Tables 2 .

Figure 3 is an illustration of EDS layered images of $2.5 \%$ and $7.5 \% \mathrm{Fe} / \mathrm{SiO}_{2}$ catalysts. Figures $1 \mathrm{a}$ and $1 \mathrm{~b}$ shows the results of SEM and Figures $2 a-b$ results of EDX. From the image of SEM it can be said that the silica is small and spherical in shape. For impregnation method the image looks agglomerated and the reaction parameters, i.e. stirring the reaction
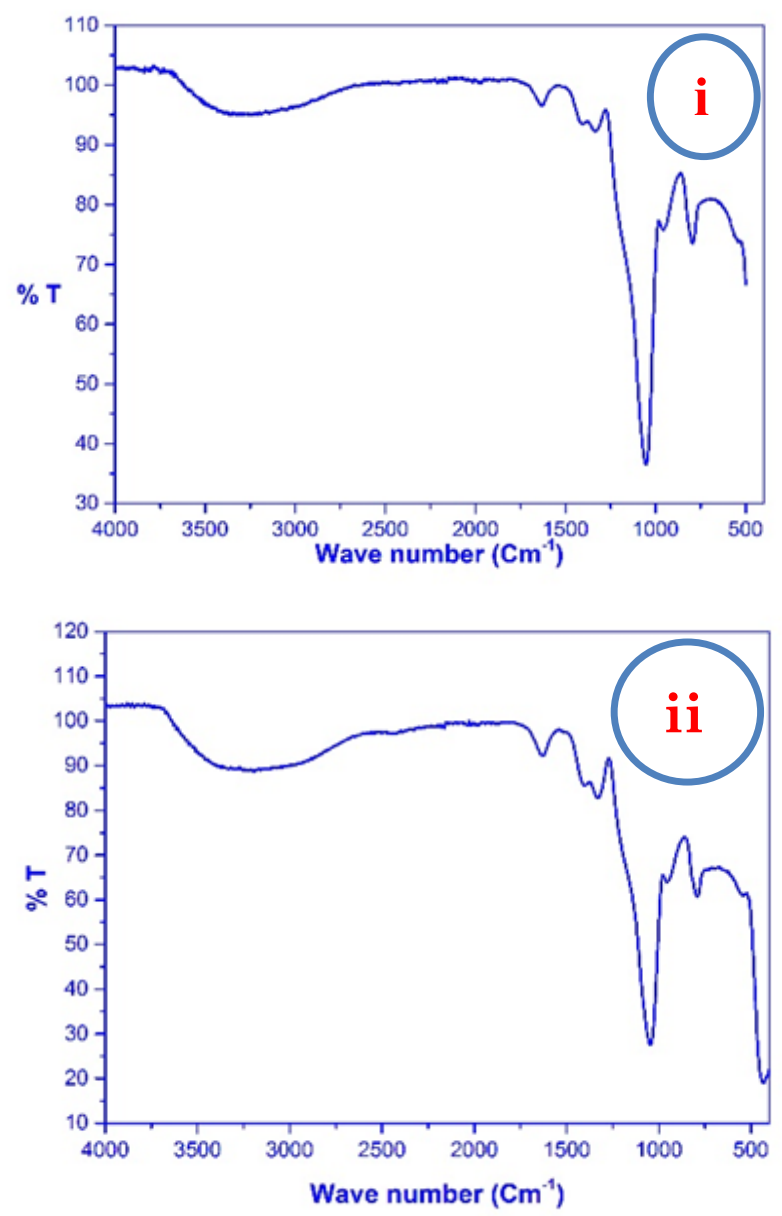

at room temperature for preparing $\mathrm{Fe} / \mathrm{SiO}_{2}$. From the Figure 3, we confirm that there are only three components that exist in the catalyst which are iron $(\mathrm{Fe})$, silica $(\mathrm{Si})$ and oxygen (O). The graph shows that this catalyst has a very large amount of silica and very less amount of iron incorporated on $\mathrm{SiO}_{2}$. The composition and weight of all three particles as shown in Figures 2a-b [23]. From these findings its evident that less amount of $2.5 \% \mathrm{Fe}$ impregnated $\mathrm{SiO}_{2}$ is active catalysts for Hanzsch reaction. With 7.5 wt.\% Fe-loaded $\mathrm{SiO}_{2}$ catalyst in Figure 2(b). Although with $7.5 \%$ loading of $\mathrm{Fe}$ on silica higher the metal loading the more concentrated the metalrepresenting dots appears (as seen in the EDX generated elemental mapping images Figure 3) [23].

\subsubsection{IR analysis of $2.5 \& 5 \% \mathrm{Fe} / \mathrm{SiO}_{2}$ catalyst}

Figures 4(i) and (ii) indicate the FTIR spectra of $2.5 \% \mathrm{Fe} / \mathrm{SiO}_{2}$ and $5 \% \mathrm{Fe} / \mathrm{SiO}_{2}$ catalysts, respectively. The spectra in Figure 4(iii) were obtained on a similar study but with Mo$\mathrm{Fe} / \mathrm{SiO}_{2}$ catalyst [10]. The spectra in Figures 4(i) and (ii) are similar and hence are expected to have the same absorption bands. There ap-

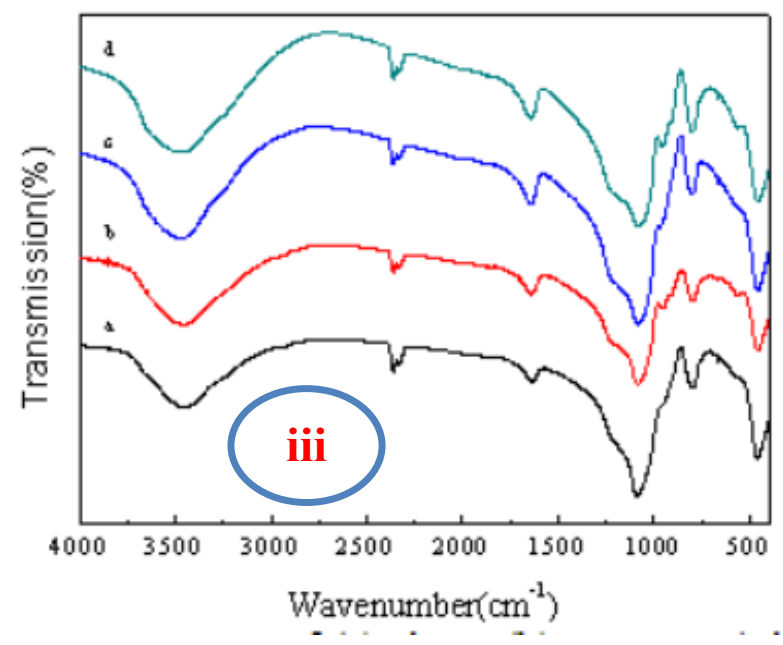

Figure 4. IR spectra of (i) $2.5 \% \mathrm{Fe} / \mathrm{SiO}_{2}$, (ii) $5 \% \mathrm{Fe} / \mathrm{SiO}_{2}$ as synthesized (iii) IR spectra of (a) $\mathrm{SiO}_{2}$, (b) $15 \% \mathrm{Mo} / \mathrm{SiO}_{2}$, (c) $10 \% \mathrm{Fe} / \mathrm{SiO}_{2}$, and (d) $15 \% \mathrm{Mo}-\mathrm{Fe} / \mathrm{SiO}_{2}$ catalyst [10].

Table 3. $2.5 \% \mathrm{Fe} / \mathrm{SiO}_{2}$ reaction with various substrates.

\begin{tabular}{|c|c|c|c|c|c|c|c|c|}
\hline $\begin{array}{l}\text { S. } \\
\text { No }\end{array}$ & Substrate & Catalyst & $\begin{array}{l}\text { Wt. of } \\
\mathrm{Fe} / \mathrm{SiO}_{2}\end{array}$ & Temp & Solvent & $\begin{array}{l}\text { Time } \\
(\mathrm{min})\end{array}$ & $\begin{array}{c}\text { Yield } \\
(\%)\end{array}$ & $\begin{array}{l}\text { Melting point for } \\
\text { product's } \\
\text { Measured Reported }\end{array}$ \\
\hline 1. & $\begin{array}{l}p- \\
\text { anisalde- } \\
\text { hyde }\end{array}$ & $\begin{array}{c}2.5 \% \\
\mathrm{Fe} / \mathrm{SiO}_{2}\end{array}$ & $0.30 \mathrm{~g}$ & $60^{\circ} \mathrm{C}$ & $\begin{array}{c}10 \mathrm{~mL} \\
\text { ethanol }\end{array}$ & 102 & 89 & $\begin{array}{lll}260-262 & 260-261 & {[25]}\end{array}$ \\
\hline 2. & $\begin{array}{l}\text { Benzalde- } \\
\text { hyde }\end{array}$ & & $0.30 \mathrm{~g}$ & $60^{\circ} \mathrm{C}$ & $\begin{array}{c}10 \mathrm{~mL} \\
\text { ethanol }\end{array}$ & 122 & 74 & $202-204 \quad 203-204$ \\
\hline
\end{tabular}


pears a curve between approximately 1625$3317 \mathrm{~cm}^{-1}$, which is attributed to the $\mathrm{H}-\mathrm{O}-\mathrm{H}$ stretching and bending vibration of the free or absorbed water, respectively [10,11]. Figure 4(iii) supports the findings as it also reported the presence of a strong band absorption at $3540 \mathrm{~cm}^{-1}$, which was assigned to the stretching vibration of the the $\mathrm{O}-\mathrm{H}$ bond. A weak band absorption was also reported at $1639 \mathrm{~cm}^{-1}$ and was assigned to flexural vibration of the $\mathrm{O}-\mathrm{H}$ bond [10]. The strong absorption band at approximately $1060 \mathrm{~cm}^{-1}$ (1089 $\mathrm{cm}^{-1}$ in literature) is attributed to the vibration of the chemical bond of Si-O-Si. The peak at approximately $570 \mathrm{~cm}^{-1}$ can be assigned to Si-O-Fe, which according to literature was reported at $578 \mathrm{~cm}^{-1}$ [10]. These evidences proves that Fe was impregnated on the silica.

\subsection{Substrate Study}

Benzaldehyde and $p$-anisaldehyde were used to study the effect of various functional groups on the yield and reaction time, especially the substituted aldehydes. The best results were obtained with $p$-anisaldehyde, which resulted in $89 \%$ yield in over a shorter duration of time with $2.5 \% \mathrm{Fe} / \mathrm{SiO}_{2}$ Table 1 . With Benzaldehyde when reaction was conducted with $2.5 \% \mathrm{Fe} / \mathrm{SiO}_{2}$ the yield was less than $74 \%$. This confirms that electron donating groups play crucial role for Hanzsch reaction which is completed in 1.5 and 1.2 hours, duration of time respectively. The melting points were observed for both products which corresponded to the values reported in literature [25]. The results are presented in Table 3.

\subsection{Solvent Study}

$p$-Anisaldehyde substrate was chosen for solvent study with acetonitrile and ethanol, and carbon tetrachloride. Hence, acetonitrile couldn't work maybe due to nonpolar behavior and carbon tetrachloride as more polar solvent. Ethanol gave the best yield and hence, it was used as the standard solvent for all the reactions. With $p$-anisaldehyde and $2.5 \% \mathrm{Fe} / \mathrm{SiO}_{2}$ at $60{ }^{\circ} \mathrm{C}$ the yield was $89 \%$ (Table 4 ).

\subsection{Gas Chromatography-Mass Spectroscopy (GCMS) Analysis}

Gas chromatography mass spectroscopy (GCMS) was used to analyze the product. For S.No. 1 Table 3, the analysis showed the presence of the most abundant fragment which corresponds to $\mathrm{m} / \mathrm{z} 252$, which according to literature is formed directly from the loss of the substrate at 4 -position [12]. The peaks at $\mathrm{m} / \mathrm{z} 224$ and $\mathrm{m} / \mathrm{z}$ corresponds to consecutive loss of ethylene [12].

The graph in Figure 5 shows the fragmentations. More graphs of the same nature are found in Appendix II. Graph of electron ionization mass spectrum of the compound that elutes at Rt 22.24 mins. After comparing the obtained the fragments to those of literature, the product structure was proposed as presented in Scheme 3.

\section{Conclusion}

In summary, a simple and easy method for the synthesis of dihydropyridines was developed by a one pot multicomponent reaction of an aldehyde; ethyl acetoacetate, ammonium acetate and ethanol under reflux condition at 60 ${ }^{\circ} \mathrm{C}$ in the presence of $\mathrm{Fe} / \mathrm{SiO}_{2}$ nano heterogeneous catalyst. The catalytic activity of $2.5 \%$ $\mathrm{Fe} / \mathrm{SiO}_{2}$ was found to be more efficient with a high yield of $89 \%$, in shorter duration of time with high selectivity. $p$-Anisaldehyde is the best substrate of choice due to its electron withdrawing character as it resulted in $80-89 \%$

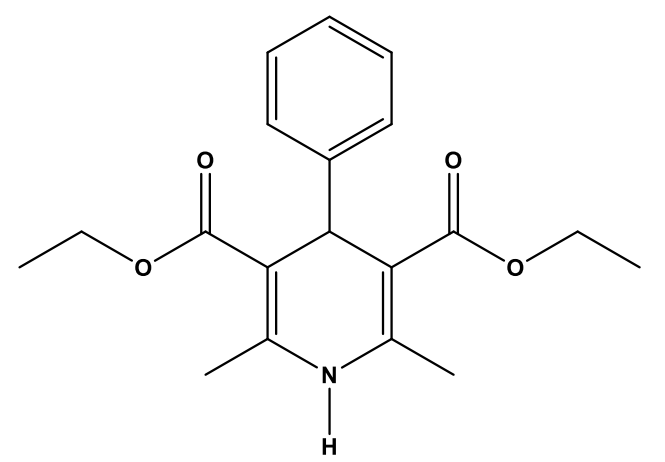

diethyl 2,6-dimethyl-4-phenyl-1,4-dihydropyridine-3,5-dicarboxylate

Scheme 3. The proposed product structure

Table 4. Summary of solvent study with $p$-anisaldehyde.

\begin{tabular}{ccccccc}
\hline Substrate & Solvent & Catalyst & Catalyst wt., g & $\begin{array}{c}\text { Temp } \\
\left({ }^{\circ} \mathrm{C}\right)\end{array}$ & $\begin{array}{c}\text { Time } \\
(\mathrm{min})\end{array}$ & $\begin{array}{c}\text { Yield } \\
\%\end{array}$ \\
\hline $\begin{array}{c}p \text { - } \\
\text { anisaldehyde }\end{array}$ & Ethanol $10 \mathrm{~mL}$ & $\begin{array}{c}2.5 \% \\
\text { Acetonitrile } 10 \mathrm{~mL}\end{array}$ & $\begin{array}{c}\mathrm{Fe} / \mathrm{SiO}_{2} \\
0.3022 \mathrm{~g} \mathrm{Fe} / \mathrm{SiO}_{2}\end{array}$ & 60 & 102 & 89 \\
$0.3035 \mathrm{~g} \mathrm{Fe} / \mathrm{SiO}_{2}$ & 60 & 122 & 74 \\
\hline
\end{tabular}




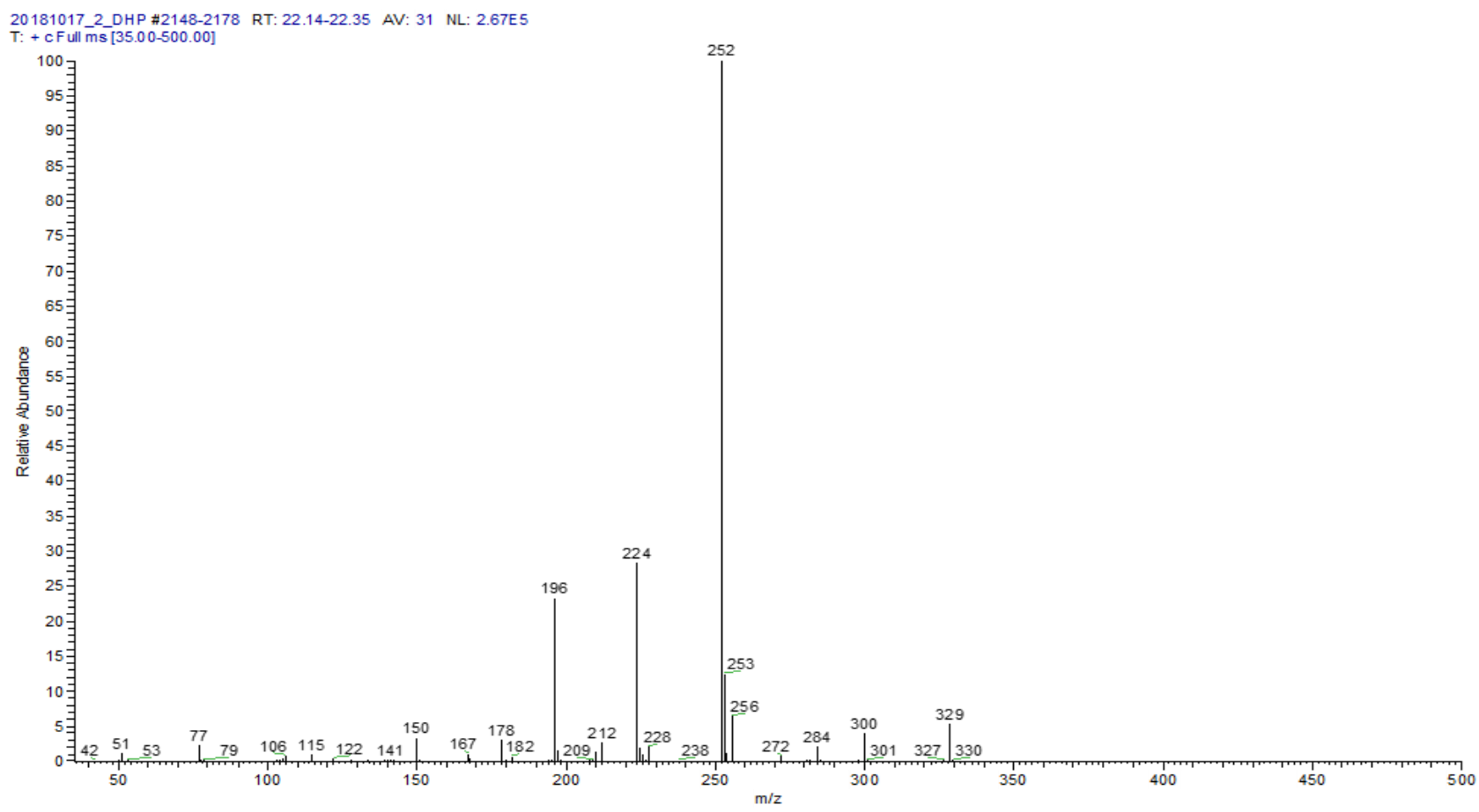

Figure 5. Electron ionization mass spectrum of the compound that elutes at Rt $22.24 \mathrm{~min}$.

yield. Yield was high with the use of $p$ Anisaldehyde as compared to benzaldehyde (with conversion in the region of 60-89). GC-MS analysis shows the basis peaks at 252 and 298 for the DHPs that were analyzed. These basis peaks are major components in DHP structures. The best conversion was obtained when $2.5 \% \mathrm{Fe} / \mathrm{SiO}_{2}$ with $p$-Anisaldehyde and ethanol at $60{ }^{\circ} \mathrm{C}$. The catalysts were characterized by IR, and SEM. From SEM analysis it confirms that spheres of $\mathrm{Fe} / \mathrm{SiO}_{2}$ were formed and $\mathrm{Fe}$ is well adhered onto the surface of $\mathrm{SiO}_{2}$, hence lead to the formation of $\mathrm{Fe} / \mathrm{SiO}_{2}$ catalysts. The IR results exhibited well formed $\mathrm{OH}$ groups at $35400 \mathrm{~cm}^{-1}$, and $\mathrm{Si}-\mathrm{O}-\mathrm{Si}$ bond at $578 \mathrm{~cm}^{-1}$ assigned to Si-O-Fe. Hence finally it can be concluded that the melting points and GC-MS results for the products obtained were confirmed with the reported melting points and GC-MS in literature. Hence in comparison with other presented procedures, our method is very quick, avoids the use of expensive reagents or high temperature and leads to improved product yields by easy procedures at reflux temperature, involves shorter reaction time, and easy to workup. Thus, an ecofriendly, and economical method is developed, with the use of a reusable, and reproducible nano $\mathrm{Fe} / \mathrm{SiO}_{2}$ catalysts and is applicable at large scale up reactions.

\section{Acknowledgement}

The authors acknowledges Dr. Stefan Louw for assisting with GC-MS analysis for the sam- ples, University of Namibia and research publications department for supporting this project.

\section{Summary statement}

No conflict of interest for each contributing author.

\section{References}

[1] Christen, D.P. (2007). Dihydropyridine calcium channel blockers for hypertension, in: D.S. Johnson, J.J. Li, eds., The art of drug synthesis, John Wiley \& Sons, Inc., Hoboken, New Jersey, pp. 159-166.

[2] Sharma, M.G., Rajani, D.P., Patel, H.M. (2017). Supplementary material from "Green approach for synthesis of bioactive Hantzsch 1,4-dihydropyridine derivatives based on thiophene moiety via multicomponent reaction". The Royal Society. Collection.

[3] Shushizadeh, M.R., Adipur, N., Kazeminezhad, I., Shojaee, M. (2015). Study of $\mathrm{Fe}_{2} \mathrm{O}_{3}, \mathrm{CuO}, \mathrm{ZnO}$ as efficient catalysts for Hantzsch reaction under different conditions. Mediterranean Journal of Chemistry, 4(3), 122-125.

[4] Saini, A., Kumar, S., Sandhu, J.S. (2008). Hantzsch reaction: Recent advances in Hantzsch 1,4-dihydropyridines. Journal of Scientific \& Industrial Research, 67, 95-111.

[5] Liu, X, Liu, B. (2017) Hantzsch Starting Directly from Alcohols through a Tandem Oxidation Process. Hindawi Journal of Chemistry, article ID 5646908. 
[6] Nasrollahi, S.M.H., Ghasemzadeh, M.A., Zolfaghari, M.R. (2018). Synthesis and Antibacterial Evaluation of Some new 1,4dihydropyridines in the presence of $\mathrm{Fe}_{3} \mathrm{O}_{4}$ Silica Sulfonic acid Nanocomposite as Catalyst. Acta Chim. Slov., 65, 1-9.

[7] Ghasemzadeh, M.A., Abdollahi-Basir, M.H. (2016). $\mathrm{Fe}_{3} \mathrm{O}_{4} @ \mathrm{SiO}_{2}-\mathrm{NH}_{2}$ Nanocomposite as a Robust and Effective Catalyst for the One-pot Synthesis of Polysubstituted Dihydropyridines. Acta Chim. Slov., 63, 627-637.

[8] Sadat Mirhosseyni, M., Nemati, F., Elhampour, A. (2017). Hollow $\mathrm{Fe}_{3} \mathrm{O}_{4} @ \mathrm{DA}-\mathrm{SO}_{3} \mathrm{H}$ : an efficient and reusable heterogeneous nanomagnetic acid catalyst for synthesis of dihydropyridine and dioxodecahydroacridine derivatives. J. Iran. Chem. Soc., 14, 791-801.

[9] Mvumvu, N. (2015). Synthesis of 1,4Didydropyidines as Potential Antimalarial Chemotype. Master of Science Thesis, Department of Chemistry, University of Cape Town.

[10] Huang, Y., Liu, Z., Liu, J., Qin, Z., Wang, J., Wen, H., Yang, K. (2011). Preparation of Mo$\mathrm{Fe} / \mathrm{SiO}_{2}$ and Catalytic Selective Oxidation of p-Xylene. Advanced Materials Research, 396$398,782-785$.

[11] Ahangaran, F., Hassanzadeh, A., Nouni, S. (2013). Surface modification of $\mathrm{Fe}_{3} \mathrm{O}_{4} @ \mathrm{SiO}_{2}$ by silane coupling agent,. International Nano Letters, 3(23), 1-5.

[12] Núñez-Vergara, L.J., Navarrete-Encina, P.A., Salas, S., Conde, B., Carbajo, J., Squella, J.A., Camargo, C. (2007). Analysis by GC-MS and GC-MS-MS of the hantzsch synthesis products using hydroxyl- and methoxy-aromatic aldehydes. Journal of Pharmaceutical and Biomedical Analysis, 44(1), 236-242.

[13] Wu, L., Wang, X. (2011). $\mathrm{P}_{2} \mathrm{O}_{5} / \mathrm{SiO}_{2}$ as a New, Efficient and Reusable Catalyst for Preparation of 4,4'-Epoxydicoumarins Under Solventfree Conditions. E-Journal of Chemistry, 8(4), 1626-1631.

[14] Farzaneh, F.F. (2017) Synthesis and Characterization of V2O5/SiO2 Nanoparticles as Efficient Catalyst for Aromatization 1,4 Dihydropyridines. Journal of Sciences, Islamic Republic of Iran. 23(4): 313-318.

[15] Safari,, J. Azizi, F., Sadeghi, M. (2015). Chitosan nanoparticles as a green and renewable catalyst in the synthesis of 1,4dihydropyridine under solvent-free conditions. New J. Chem., 39, 1905-1909.

[16] Maleki, B.H., Tayebee, R., Spehr, Z., Kermanian, M. (2012). A Novel, Heterogeneous and Recyclab le Polymeric Catalyst for the OnePot Synthesis of Polyhydroquinoli ne and 1,8Dioxohexahy droacridine Derivatives Under Solvent-Free Conditions. Acta Chim. Slov., $59,814-823$.
[17] Tekale, S.U., Pagore, V.P., Kauthale, S.S., Pawar, R.P. (2014). $\mathrm{La}_{2} \mathrm{O}_{3} / \mathrm{TFE}$ : An efficient system for room temperature synthesis of Hantzsch polyhydroquinolines. Chinese Chemical Letters, 25, 1149-1152.

[18] Wang, L.M., Sheng, J., Zhang, L., Han, J.W., Fan, Z.Y., Tian, H., Qian, C.T. (2005). Facile $\mathrm{Yb}(\mathrm{OTf})_{3}$ promoted one-pot synthesis of polyhydroquinoline derivatives through Hantzsch reaction. Tetrahedron, 61, 1539-1543.

[19] Donelson, J.L., Gibbs, R.A., De, S.K. (2006). An efficient one-pot synthesis of polyhydroquinoline derivatives through the Hantzsch four component condensation. J. Mol. Catal. A: Chem., 256, 309-311.

[20] Kiasat, A.R., Nazari, S., Davarpanah, J. (2014). B-Cyclodextrin-polyurethane polymer: a neutral and eco-friendly heterogeneous catalyst for the one-pot synthesis of 1,4dihydropyridine and polyhydroquinoline derivatives via the Hantzsch reaction under solvent-free conditions. J. Serb. Chem. Soc., 79(4), 401-409.

[21] Nasr-Esfahani, M., Montazerozohori, M., Maejo, R.R. (2014). An efficient Hantzsch synthesis of 1,4-dihydropyridines using ptoluenesulfonic acid under solvent-free condition. Int. J. Sci. Technol., 8(01), 32-40.

[22] Wilson, K., Clark, J.H. (2000). Solid acids and their use as environmentally friendly catalysts in organic synthesis. Pure Appl. Chem., $72,1313-1319$.

[23] Debache, A., Ghalem, W., Boulcina, R., Belfaitah, A., Rhouati, S., Carboni, B. (2009). An efficient one-step synthesis of 1, 4dihydropyridines via a triphenylphosphinecatalyzed three-component Hantzsch reaction under mild conditions. Tetrahedron Lett., 50, 5248-5250.

[24] Rahman, A., Rajasekhar Pullobhotla, V.S.R., Jonnalagadda, S.B. (2008). Selective oxidation of p-nitrobenzyl alcohol to pnitrobenzaldehyde with $10 \% \mathrm{Ni}$ silica with $30 \% \mathrm{H}_{2} \mathrm{O}_{2}$ in acetonitrile solvent. Catalysis Communications, 9, 2417-2421.

[25] Maleki, B., Tayebee, R., Sepehr, Z., Keranian., M. (2012). A Novel, Heterogeneous and Recyclable Polymeric Catalyst for the OnePot Synthesis of Polyhydroquinoline and 1,8Dioxohexahydroacridi ne Derivatives Under Solvent-Free Conditions. Acta Chim. Slov., 59, 814-823.

[26] Anbia, M., Ali, M., Al-Ghaffarinejad, A. (2018). Humidity sensitive behavior of $\mathrm{Fe}\left(\mathrm{NO}_{3}\right)_{3}$-loaded mesoporous silica MCM-41. Sensors and Actuators B: Chemical, 193, 225229. 


\section{Appendices}

Appendix I (IR)

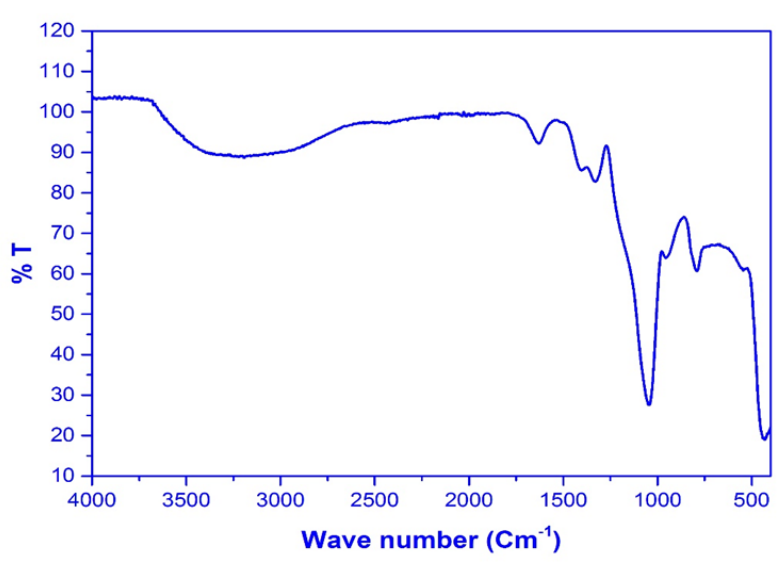

IR: $2.5 \mathrm{Fe} / \mathrm{SiO}_{2}$

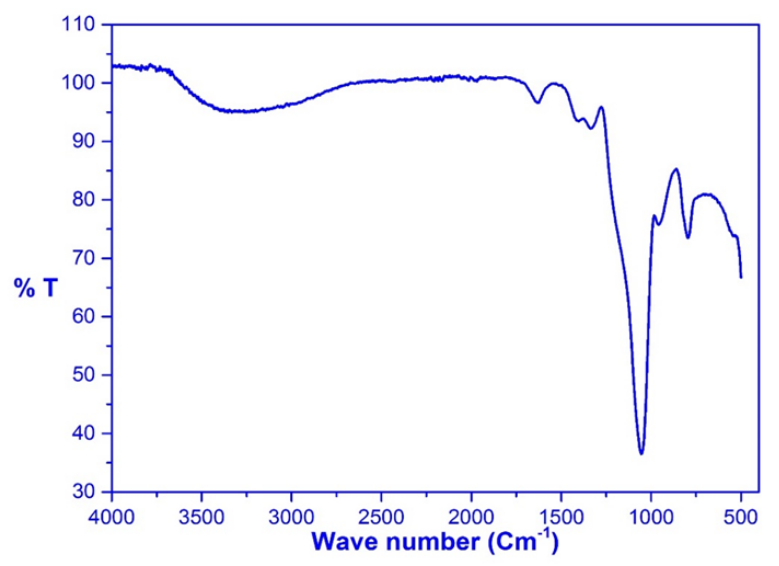

IR: $5 \% \mathrm{Fe} / \mathrm{SiO}_{2}$

Appendix II (GC-MS)

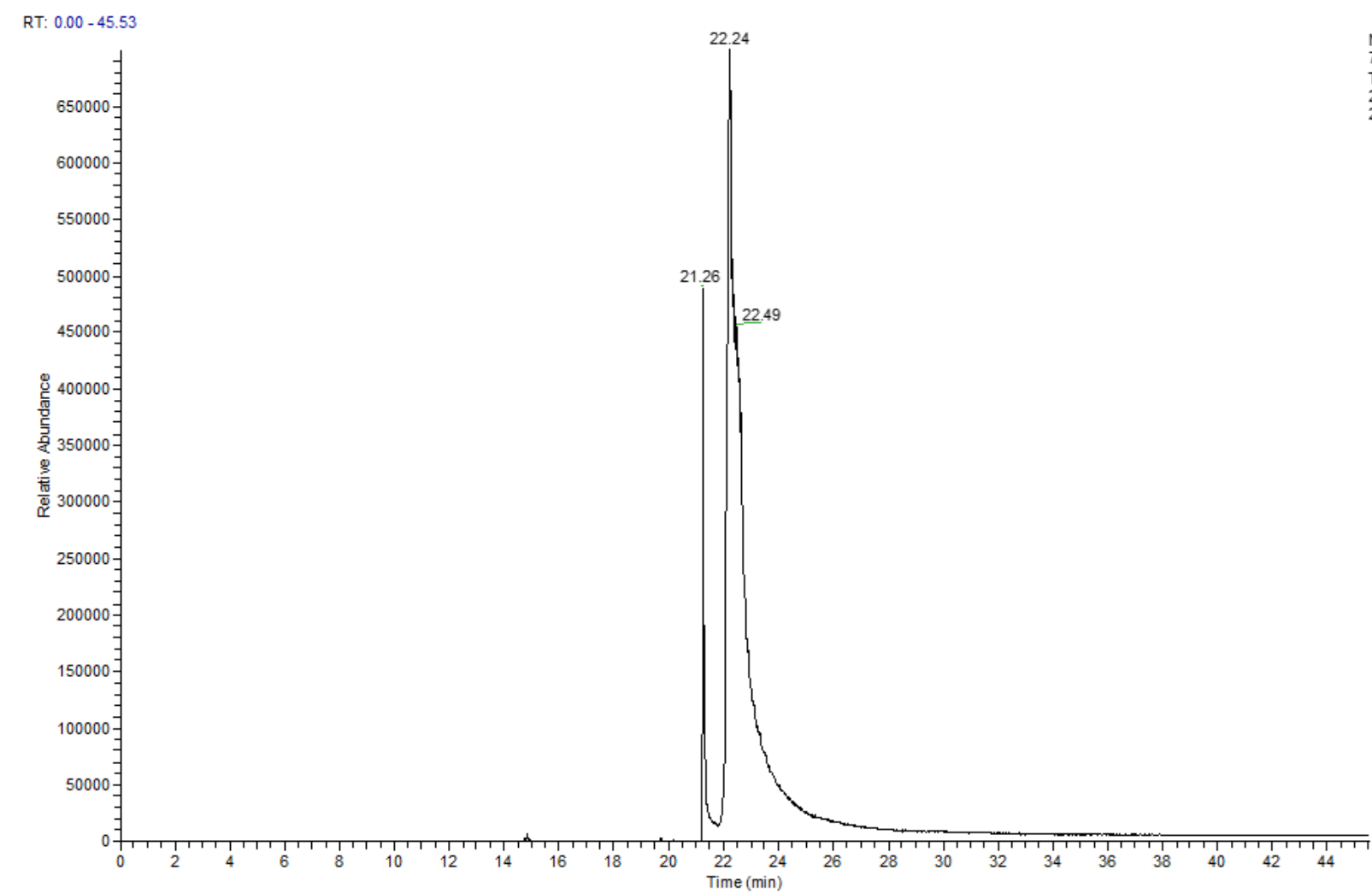

Total ion chromatogram of sample DHP. 


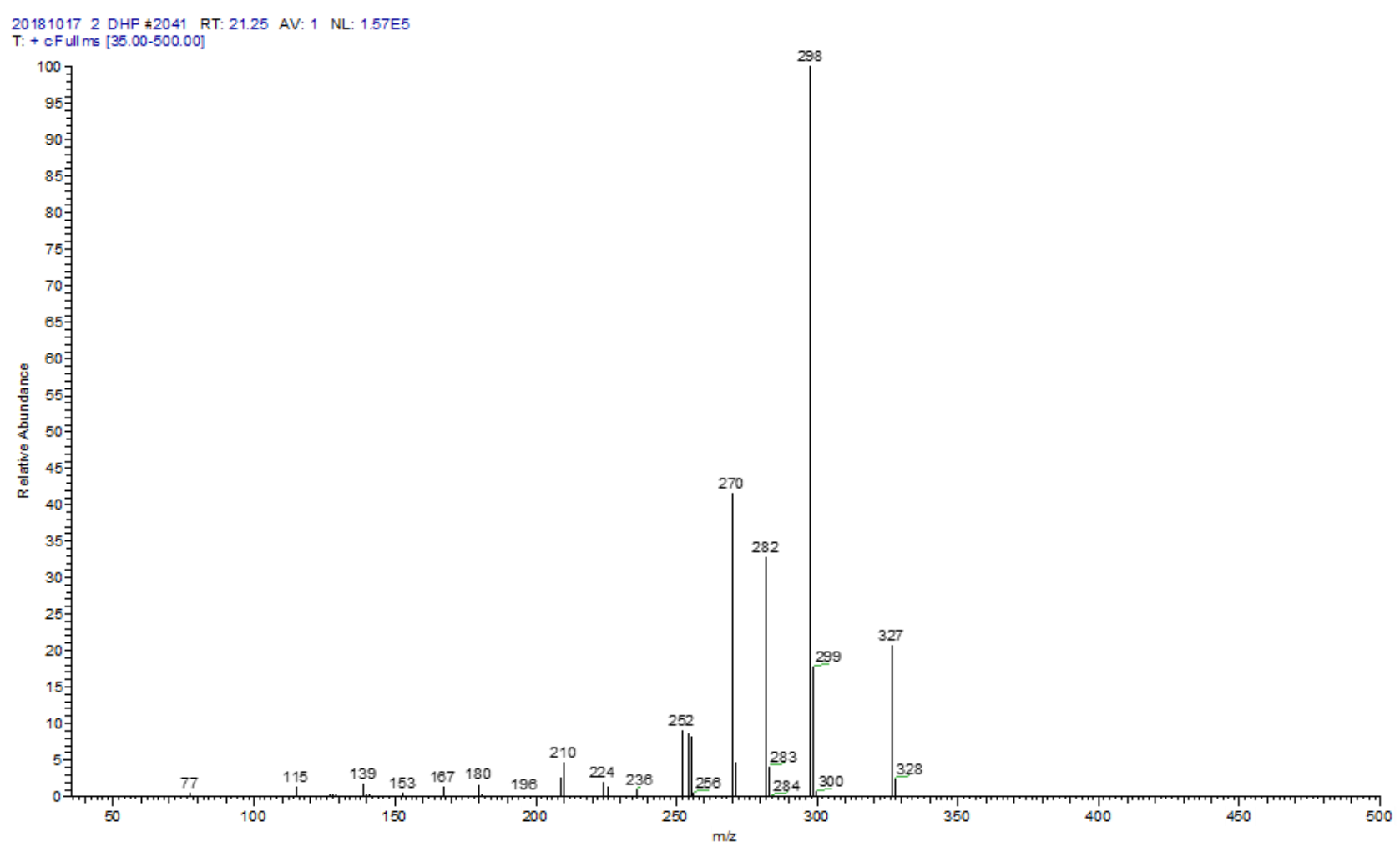

Electron ionization mass spectrum of the compound that elutes at Rt $21.26 \mathrm{~min}$.

20181017_2_DHP \#2148-2178 RT: $22.14-22.35$ AV: 31 NL: $2.67 E 5$

$\mathrm{T}:$ + c o Full ms [35.00-500.00]
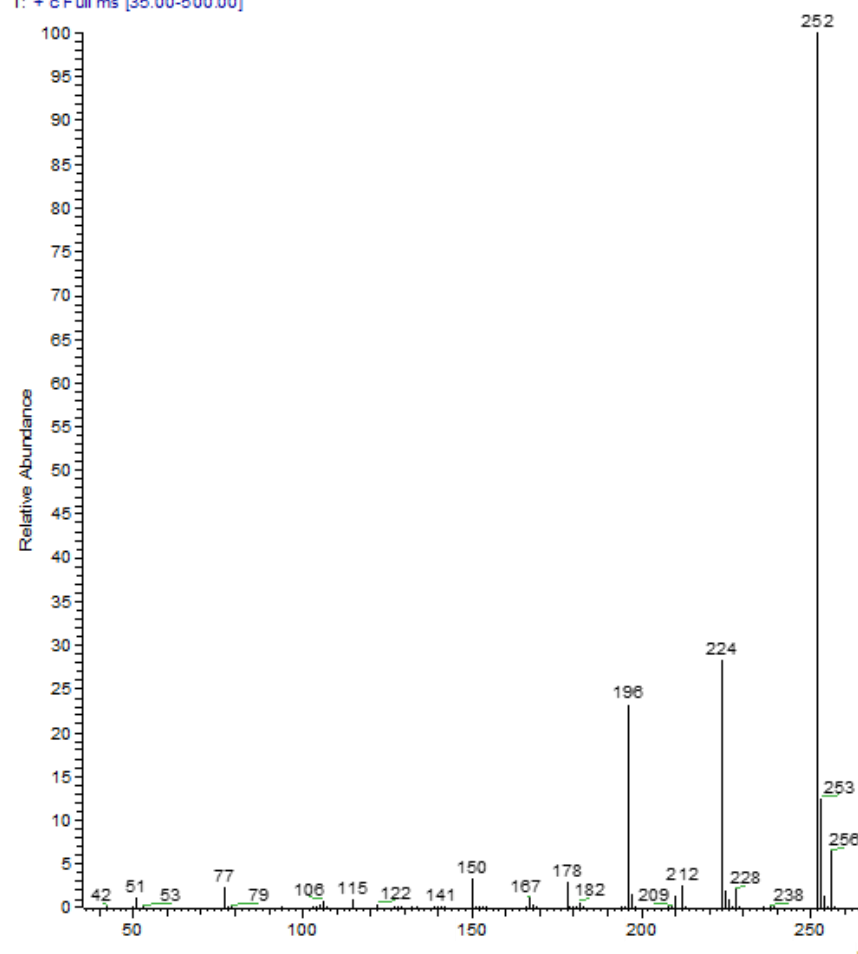

Electron ionization mass spectrum of the compound that elutes at Rt $22.24 \mathrm{~min}$. 


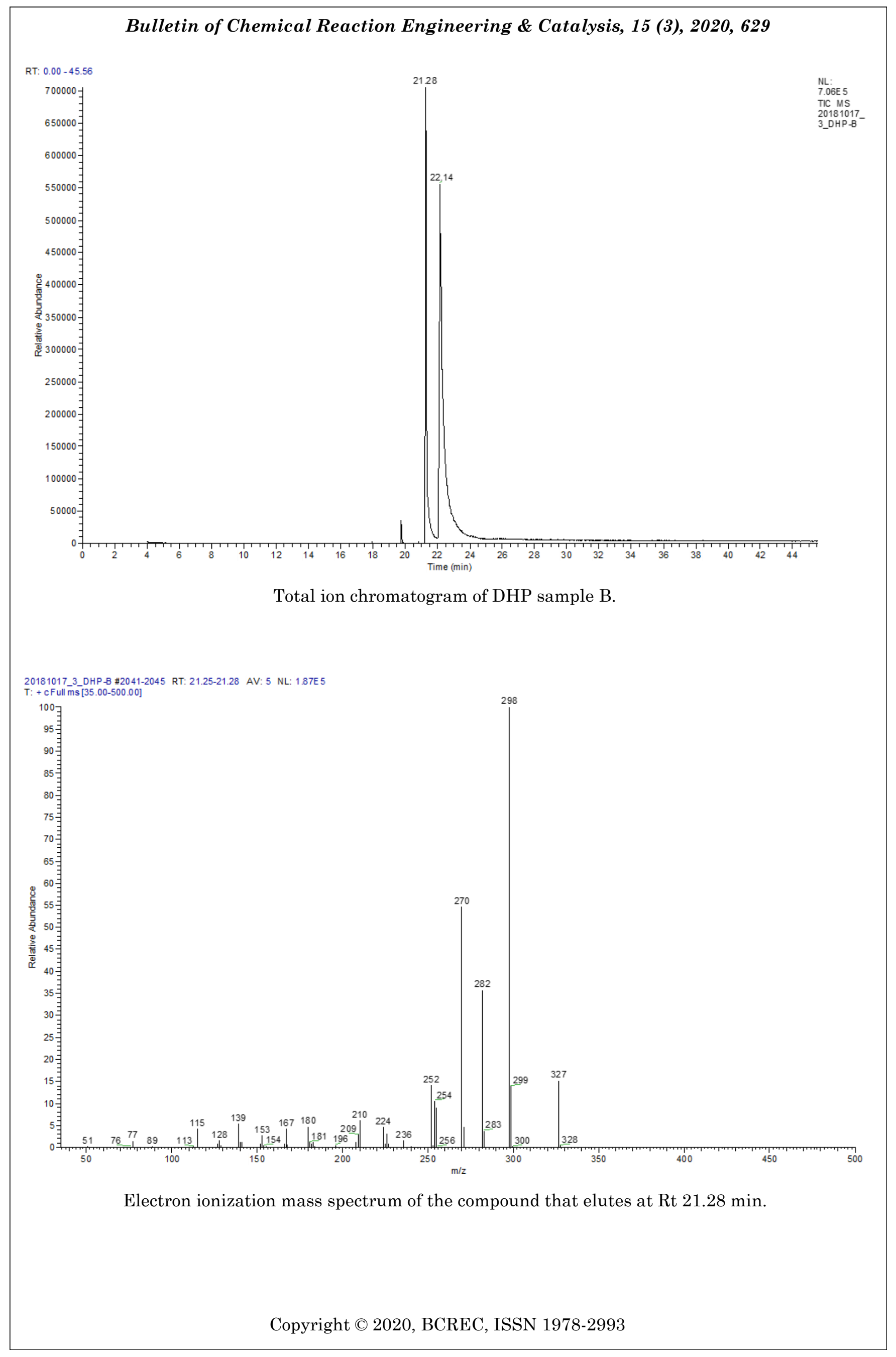


20181017_3_DHP-B \#2141-2166 RT: 22.08-22.27 AV: 26 NL: $1.88 E 5$

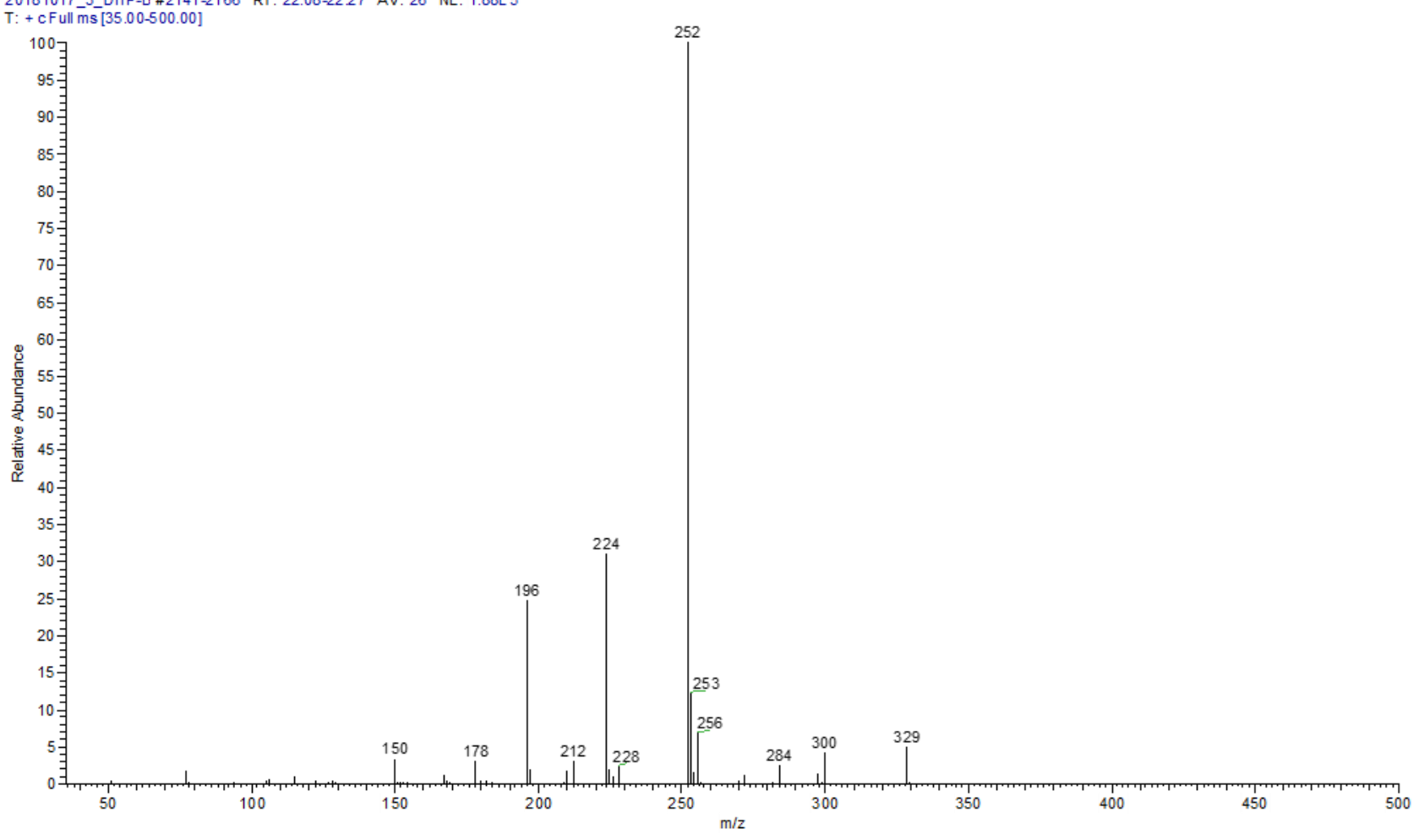

Electron ionization mass spectrum of the compound that elutes at Rt 22.14. 